\title{
Small Field of View Scintimammography Gamma Camera Integrated to a Stereotactic Core Biopsy Digital X-Ray System
}

\author{
A. G. Weisenberger, F. Barbosa, Member, IEEE, T. D. Green, R. Hoefer, C. Keppel, B. Kross, S. Majewski, V. Popov,
} R. Wojcik, and D. C. Wymer

\begin{abstract}
A small field of view gamma camera has been developed for integration with a commercial stereotactic core biopsy system. The goal is to develop and implement a dual-modality imaging system utilizing scintimammography and digital radiography to evaluate the reliability of scintimammography in predicting the malignancy of suspected breast lesions from conventional X-ray mammography. The scintimammography gamma camera is a custom-built mini gamma camera with an active area of $5.3 \mathrm{~cm} \times 5.3 \mathrm{~cm}$ and is based on a $2 \times 2$ array of Hamamatsu R7600-C8 position-sensitive photomultiplier tubes. The spatial resolution of the gamma camera at the collimator surface is $<\mathbf{4} \mathbf{~ m m}$ full-width at half-maximum and a sensitivity of $\sim 4000 \mathrm{~Hz} / \mathrm{mCi}$. The system is also capable of acquiring dynamic scintimammographic data to allow for dynamic uptake studies. Sample images of preliminary clinical results are presented to demonstrate the performance of the system.
\end{abstract}

Index Terms-Gamma-ray detectors, scintimammography, $\mathrm{X}$-ray imaging.

\section{INTRODUCTION}

$\mathbf{T}$ HE radiopharmaceutical ${ }^{99 m} \mathrm{Tc}$-sestamibi is known to concentrate in breast tumors and has been undergoing evaluation as a means of detecting breast cancer prior to biopsy [1]. The positive predictive value of standard mammography is between $10 \%-30 \%$ [2]. Studies have shown that scintimammography has the potential to provide early indication of breast cancer and could reduce the number of needle biopsies of benign tumors [3]-[5]. There have been studies involving scintimammography using conventional gamma cameras [6] and application-specific systems [7], [8]. The use of scintimammography as an aid for tumor biopsy has

Manuscript received October 12, 2000; revised April 9, 2002. The Southeastern Universities Research Association (SURA) operates the Thomas Jefferson National Accelerator Facility for the U.S. Department of Energy under Contract DE-AC05-84ER40150.

A. G. Weisenberger, F. Barbosa, B. Kross, S. Majewski, V. Popov, and R. Wojcik are with the Thomas Jefferson National Accelerator Facility, Newport News, VA 23606 USA.

C. Keppel is with the Thomas Jefferson National Accelerator Facility, Newport News, VA 23606 USA, and also with the Department of Physics, Hampton University, Hampton, VA 23668 USA.

T. D. Green is with the Department of Physics, Hampton University, Hampton, VA 23668 USA.

R. Hoefer and D. C. Wymer are with the Riverside Regional Medical Center, Newport News, VA 23601 USA.

Digital Object Identifier 10.1109/TNS.2002.803778 also been discussed [9] and the application of dual-modality imaging as an aid to breast cancer diagnosis has been reported earlier [10]. We report on the innovative development of a dual modality imaging system based on a custom-built compact scintimammography gamma camera which is mounted to a Fischer Imaging ${ }^{1}$ digital X-ray stereotactic core biopsy system. The mini gamma camera is optimized for application-specific use in situ with a commercially available X-ray guidance system for stereotactically guided core needle breast biopsy in order to obtain co-registered gamma-ray/X-ray image of a specific $5 \mathrm{~cm} \times 5$-cm region of the breast.

Several groups have reported extensive work implementing position-sensitive photomultiplier tubes (PSPMTs) for gamma imaging applications [11]-[13]. We have been developing application-specific gamma cameras based on PSPMTs [14]-[16]. The detector design we utilize in this project makes use of an array of small PSPMTs. The concept of a small field of view gamma breast imager using a $2 \times 2$ array of compact PSPMTs coupled to arrays of crystal scintillators was conceived and first tried in a laboratory prototype by Dr. R. Pani and his group at the University "La Sapienza," Rome, Italy [17], [18].

Stereotactic breast biopsy is an X-ray-guided method for localizing and sampling suspect breast lesions identified from a patient's mammogram. The patient lies prone on a mammography table and the affected breast is positioned in a special compression paddle that has a $5-\mathrm{cm} \times 5$-cm-square opening. Localization of a specific lesion within a breast is based on measurements of the position of the lesion on two $\mathrm{X}$-ray images (a stereo pair) of the breast taken from different angles $(+/-15$ degrees). The radiologist selects the center of the lesion, mass, or calcification and a computer generates the Cartesian coordinates of the targeted lesion. Once the exact location is calculated, one of several devices is employed to obtain a tissue sample for biopsy. Only 19\% of the biopsies performed on women with suspected breast cancer based on their mammograms end up being positive for cancer [19].

The clinical goal is to obtain data on the reliability of scintimammography in predicting the malignancy of suspected breast lesions with the objective of reducing the typically large number of false positives associated with conventional X-ray mammography. A clinical study is underway and examples of two patient

\footnotetext{
${ }^{1}$ Fischer Imaging Corporation, Denver CO.
} 


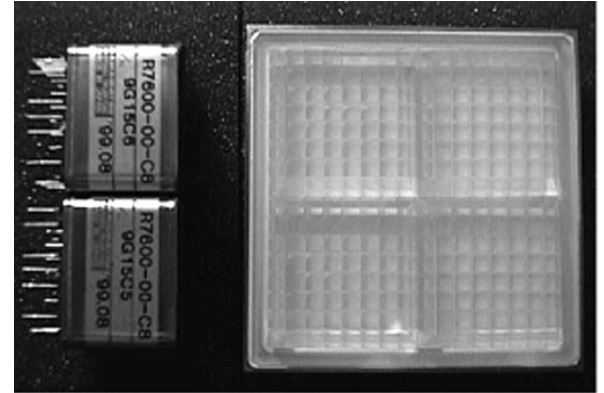

Fig. 1. Photograph of two of the PSPMTs and the $\mathrm{NaI}(\mathrm{Tl})$ crystal array with the light guide in place.

studies are presented here to demonstrate the operation of the system.

This paper is organized as follows. In Section II is a detailed description of the detector head we developed. In Section III, we describe the overall system operation and, in Section IV, we finish with a conclusion.

\section{Mini Gamma Camera Detector System}

The Jefferson-Lab-built mini gamma camera with an active area of $5.3 \mathrm{~cm} \times 5.3 \mathrm{~cm}$ is based on a $2 \times 2$ array of Hamamatsu ${ }^{2}$ R7600-00-C8 PSPMTs. Each of the R7600-C8 PSPMTs has a minimum effective area of $22 \times 22 \mathrm{~mm}^{2}$ (see Fig. 1).

The PSPMT has $4 x+4 y$ cross-plate anodes such that each PSPMT has eight outputs. A Jefferson-Lab-constructed "subtractive resistive" charge division circuit is used to combine the signals from all of the PSPMTs, resulting in a total of four outputs (two in $x$-direction and two in $y$ direction). Optically coupled to the array of PSPMTs via a light guide is a Bicron ${ }^{3}$ scintillator array which is a $16 \times 16$ matrix of $3 \mathrm{~mm} \times 3 \mathrm{~mm}$ $\times 6 \mathrm{~mm} \mathrm{NaI}(\mathrm{Tl})$ crystal scintillator pixels in which each element is separated by a $0.3-\mathrm{mm}$ light-diffusing septum. The light guide serves to optically mix the light to facilitate light sharing across PSPMTs so that the crystal matrix can be imaged without breaks because of dead space between the individual PSPMTs. Several larger prototypes of this type of camera were tested at the University of Virginia Medical Center ${ }^{4}$ [20].

\section{A. Subtractive Resistive Readout Circuit}

In the Jefferson Lab readout circuit, the $x$ and $y$ signals from each PSPMT are connected together to produce a crossed wire $8 \times 8$ readout. Standard charge division readout causes the pixel images formed from the signals of the last two rows of pixels at the edges of the detector to overlap and become indistinguishable. Increasing the resistors between the last two readout wires, as suggested by others [21], offers only a slight improvement. A new readout circuit was designed such that the individual anode wire signals are amplified and sent to both a summing and a subtraction circuit (see Fig. 2). A fraction of the resulting sum is fed into the subtraction circuit and deducted from each signal.

\footnotetext{
${ }^{2}$ Hamamatsu Corporation, Bridgewater, NJ.

${ }^{3}$ Bicron, Newbury, OH.

${ }^{4}$ M. Williams, Department of Radiology, University of Virginia Medical Center, Charlottesville, VA.
}

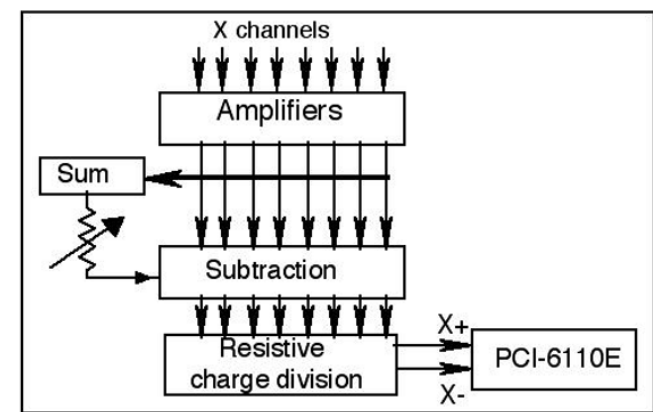

Fig. 2. Block diagram of subtractive resistive readout electronics.

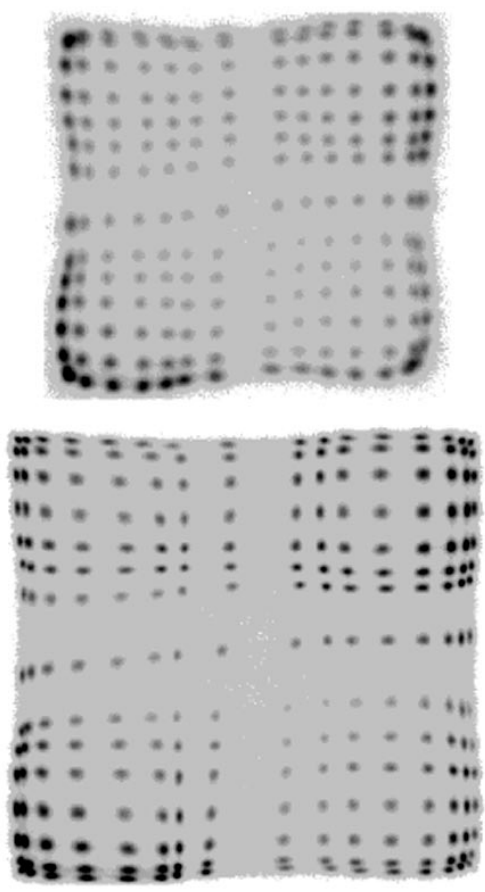

Fig. 3. Comparison of charge division with increased resistance edge resistors (top) and the subtractive resistive readout (bottom) in resolving the $3 \times 3$ $\times 6-\mathrm{mm} \mathrm{NaI}(\mathrm{Tl})$ crystal array.

By subtracting a percentage of the sum from each signal before it enters a charge division readout chain, edge effects are greatly reduced. The circuit causes the expansion of the field of view of the camera to the very edges of the PSPMT array. In Fig. 3 is an example of images obtained by flooding the $\mathrm{NaI}(\mathrm{Tl})$ crystal array with the gamma emission of Co-60. Shown is an image obtained with a standard charge division readout and one obtained with the new subtractive resistive readout. Notice two extra rows and columns of crystals now resolvable at the edge region are not separated with standard charge division. The useful active area increased from $\sim 46 \mathrm{~mm} \times 52.5 \times 52.5 \mathrm{~mm}$.

\section{B. Gamma-Ray Image Generation}

The final image is formed by mapping the data identified to belong to a particular crystal element into that crystal's appropriate pixel in the final image. A separate energy window is also defined for each crystal element. Please see Fig. 4 for a sample of a normalized energy spectrum obtained for Tc $99 \mathrm{~m}$ obtained 


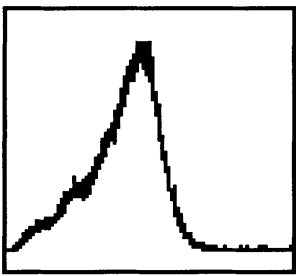

Fig. 4. Normalized Tc99m energy spectrum for the $\mathrm{NaI}(\mathrm{Tl})$ array.

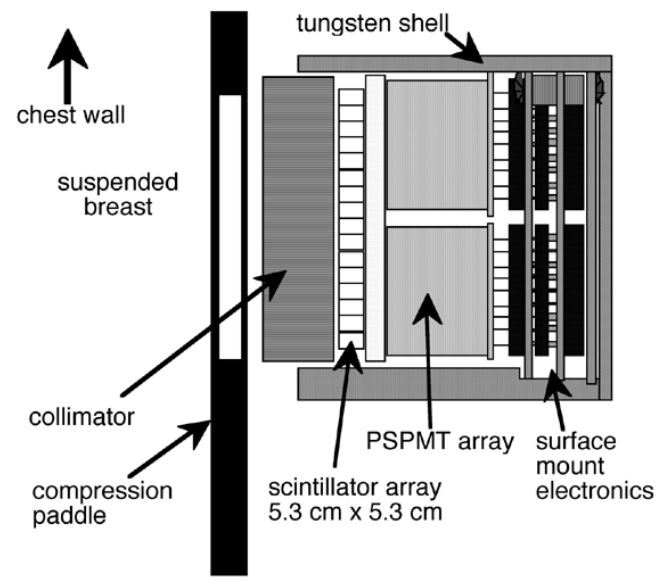

Fig. 5. Schematic of the mini gamma camera detector head.

using the individual energy normalization factor for each element of the array. The overall energy resolution for the $\mathrm{NaI}(\mathrm{Tl})$ array is $17.5 \%$ for $\mathrm{Tc} 99 \mathrm{~m}(140 \mathrm{keV})$.

\section{Data Acquisition System}

The data acquisition system is based on an Apple Macintosh G3 workstation installed with a National Instruments Inc. ${ }^{5}$ fourchannel ADC PCI card model PCI-6110E that is controlled by a software product called Kmax from Sparrow Corporation ${ }^{6}$. The system is capable of saving the imaging data in list mode with time stamps for later replay to study the dynamic aspects of the radio-pharmaceutical uptake in the patient.

\section{Detector Head Placement}

Shown in Fig. 5 is a schematic diagram indicating the major components of the detector head as positioned to obtain an image of the region of the breast.

Because of the close proximity to the patient on nearly all sides of the detector head in the cranial caudal (CC) orientation, a tungsten shell was necessary to insure adequate shielding all around the detector head. No stereo views are acquired with the mini gamma camera. With a high-sensitivity lead collimator, the computed resolution of the gamma camera at the collimator surface is $3.8 \mathrm{~mm}$ FWHM as confirmed by phantom measurements. The gamma camera sensitivity was measured to be $\sim$ $4000 \mathrm{cps} / \mathrm{mCi}$.

As mentioned above, the compact gamma camera is attached to a Fischer Imaging Inc. digital X-ray stereotactic biopsy

${ }^{5}$ National Instruments Inc., Austin, TX.

${ }^{6}$ Sparrow Corporation. Daytona Beach, FL.

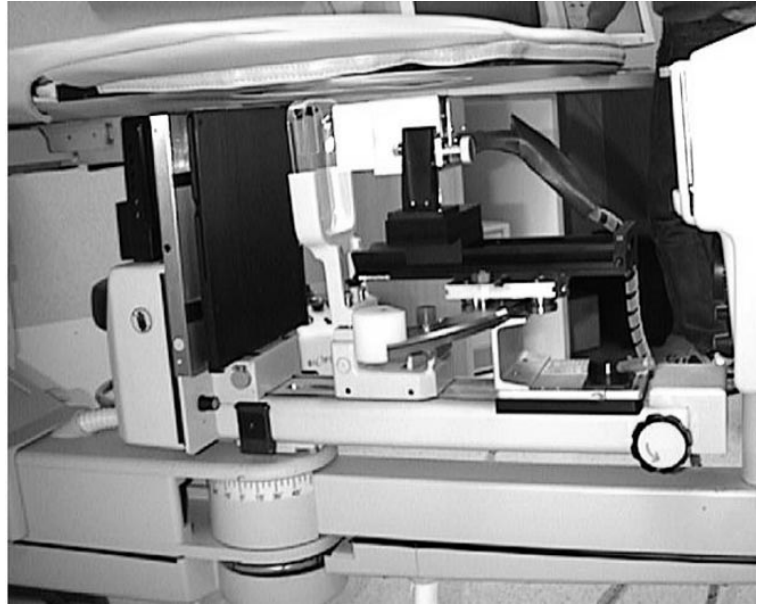

(a)

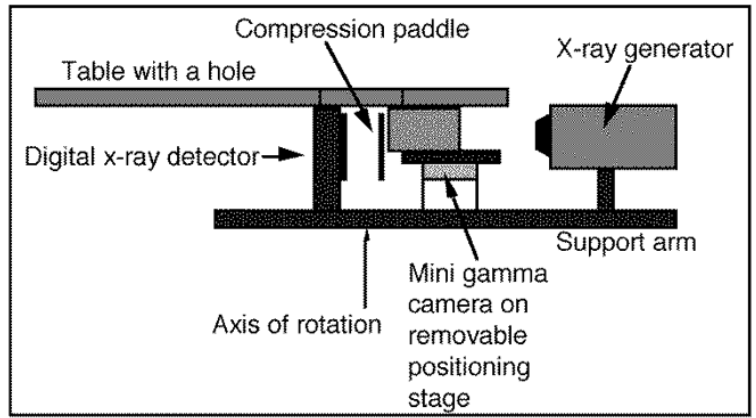

(b)

Fig. 6. (a) Mini gamma camera (white rectangular box) in place in the Fischer core biopsy table. (b) Schematic indicating the geometry of the arrangement.

system. A photograph and schematic diagram of the clinical setup is shown in Fig. 6.

\section{SYSTEM OPERATION}

The women included in the ongoing Riverside Regional Medical Center Institutional Review Board (IRB)-approved study are individuals who have been scheduled for breast biopsy because of suspicious regions identified on their mammograms. On the pre-op, one or two days prior to the actual biopsy operation visit, the patient is normally positioned on the stereo table, the breast compressed, and three digital Xx-ray views are obtained: a straight-on scout view and two stereo views (+ and -15 degrees). These views are taken to plan for the actual biopsy procedure which typically occurs one or two days later. After the pre-op X-ray images are obtained but while the breast is still under compression, the patients are then injected with $25 \mathrm{mCi}(925 \mathrm{MBq})$ of ${ }^{99 m} \mathrm{Tc}$-sestamibi and imaged for $10 \mathrm{~min}$ with the mini gamma camera in the scout view only. Dupont markets ${ }^{99 m} \mathrm{Tc}$-sestamibi as MiraLuma. The patients are then imaged with the standard Toshiba model GCA-901A gamma camera is equipped with a high-resolution collimator so that a lower resolution reference image can be obtained.

The mini gamma camera image acquisition is started just seconds before the dose is injected. The data acquisition system is capable of storing the time stamped event data in list mode to obtain a dynamic imaging record of the uptake of the MiraLuma in the area being imaged. This allows us to replay the data at any 


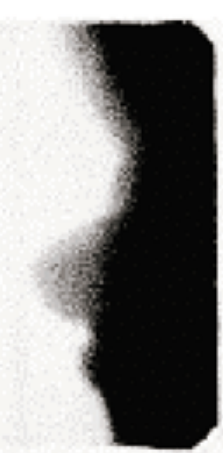

(a)

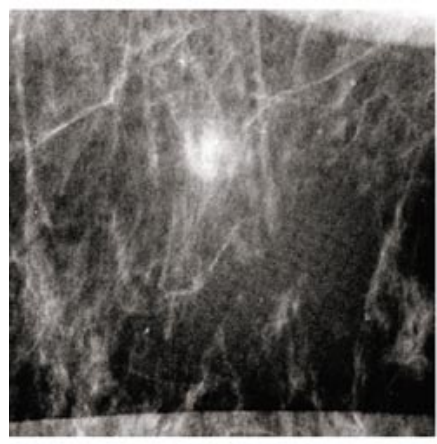

(c)

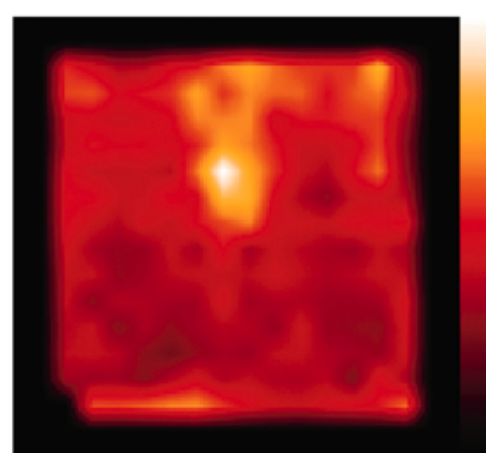

(b)

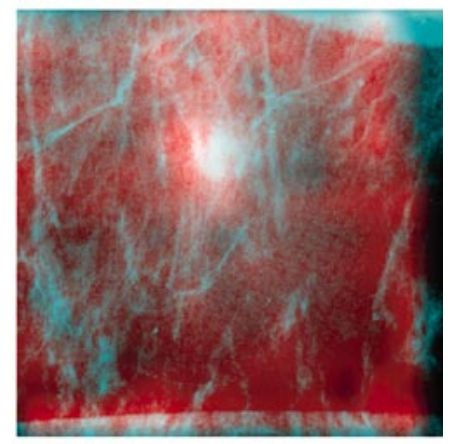

(d)
Fig. 7. (a) Toshiba camera image. (b) Scout mini gamma camera image (c) Scout digital core biopsy X-ray image. (d) A co-registered overlay image of the mini gamma camera image with the digital X-ray blue image. The lesion was classified as invasive ductal carcinoma, well differentiated and $0.8 \mathrm{~cm}$ in size.

chosen time interval to investigate the dynamic nature of the MiraLuma uptake for different tumors.

\section{A. Example Studies}

We present two cases that demonstrate the clinical operation of the imaging system. As previously mentioned, a clinical study is presently underway and the results will be evaluated when sufficient clinical data are obtained. For each case the patient was first positioned, her breast placed under compression, and the technologist using the mammogram films located the suspected region with the Fischer digital $\mathrm{x}$-ray system. Two stereo $\mathrm{X}$-ray views $\left(-15^{\circ}\right.$ and $\left.+15^{\circ}\right)$ and one scout $\left(0^{\circ}\right.$ to the normal $)$ were obtained. After the radiologist was satisfied with the information required for the actual biopsy, the patient was kept in compression then injected with MiraLuma and the gamma imaging started. The duration of the image acquisition was 10 min. After the image acquisition, the patient was moved to a room housing a standard Toshiba clinical gamma camera. The patient was placed in the standard scintimammography prone position on a table with the breasts hanging pendantly and was imaged for $10 \mathrm{~min}$.

The actual biopsy procedure is done usually within two days after the pre-op procedure. Since no stereo gamma images are obtained, we assume that the actual region from which a tissue sample is taken is the same identified by the radiologist in the scout and stereo X-ray images. The only co-registered images are the scout X-ray image and the scout gamma image.
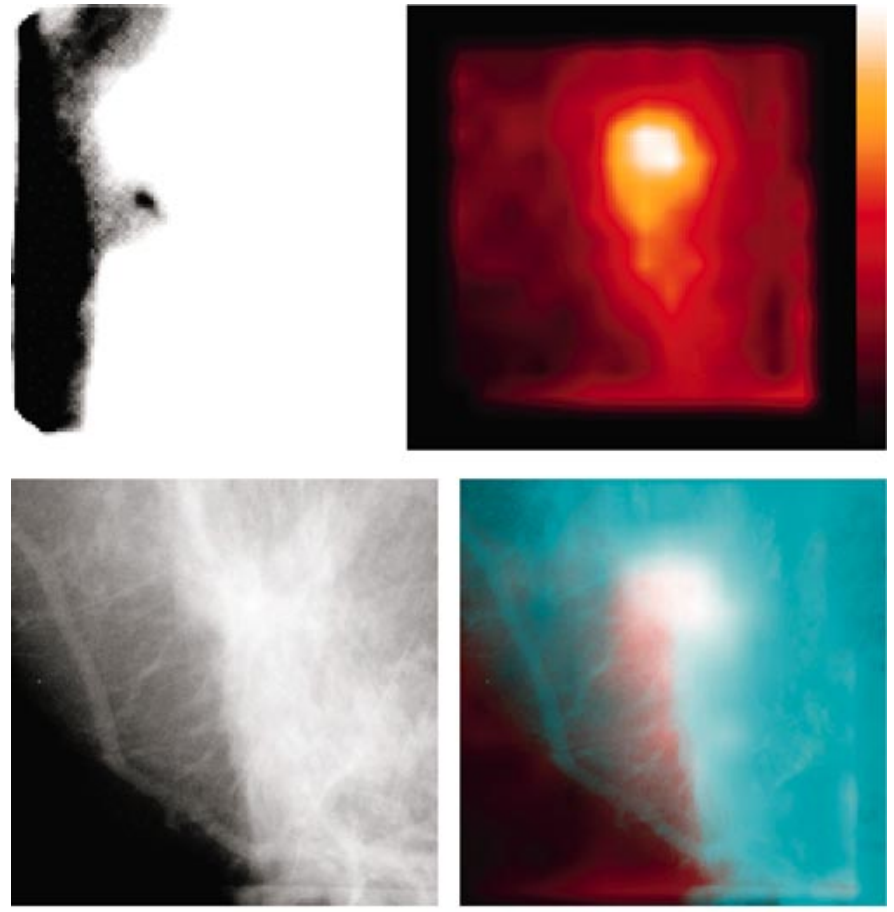

Fig. 8. These images are in the same sequence as in Fig. 7. The biopsy returned positive for a malignancy with the lesion classified as an infiltrating carcinoma, $2.8 \mathrm{~cm}$ in size.

Figs. 7 and 8 are examples of the images obtained for two patients. Fig. 8 is a case in which a compression of $7 \mathrm{~cm}$ with a $\mathrm{CC}$ view of the left breast was used for this $180 \mathrm{lb}$ 77-year-old patient. The biopsy for this patient returned positive for a malignancy for the suspected region. The lesion was classified as invasive ductal carcinoma, well differentiated and $0.8 \mathrm{~cm}$ in size.

Fig. 8 is another case in which a compression of $6 \mathrm{~cm}$ with a CC view of the right breast was used for this 192-lb 56-year-old patient. The biopsy for this patient returned positive for a malignancy with the lesion classified as an infiltrating carcinoma, predominantly lobular and $2.8 \mathrm{~cm}$ in size.

\section{B. Dynamic Imaging}

With the system, it is possible to replay imaging list mode data obtained with the mini gamma camera. We have developed an analysis program using the Interactive Data Language (IDL) package from Research Systems Inc. ${ }^{7}$ that allows the user to select the time interval desired to generate a time series of images. It is also possible to select regions of interest (ROIs) to obtain a time activity curve for the chosen ROI. By replaying the event data taken during the patient study shown in Fig. 8 a time series of images was obtained with the mini gamma camera. This is shown in Fig. 9.

The series of images represent the first $6 \mathrm{~min}$ of image acquisition that was started just as the $25 \mathrm{mCi}(925 \mathrm{MBq})$ dose of MiraLuma was injected intravenously into the patient's arm. Each of the images represents a new image acquisition taken every minute for time of $1 \mathrm{~min}$. It is clear from the images that the image of the tumor becomes visible within 2 min after the injection. In Fig. 10 is a plot showing the dynamic nature of the

${ }^{7}$ Research Systems Inc., Boulder, CO. 

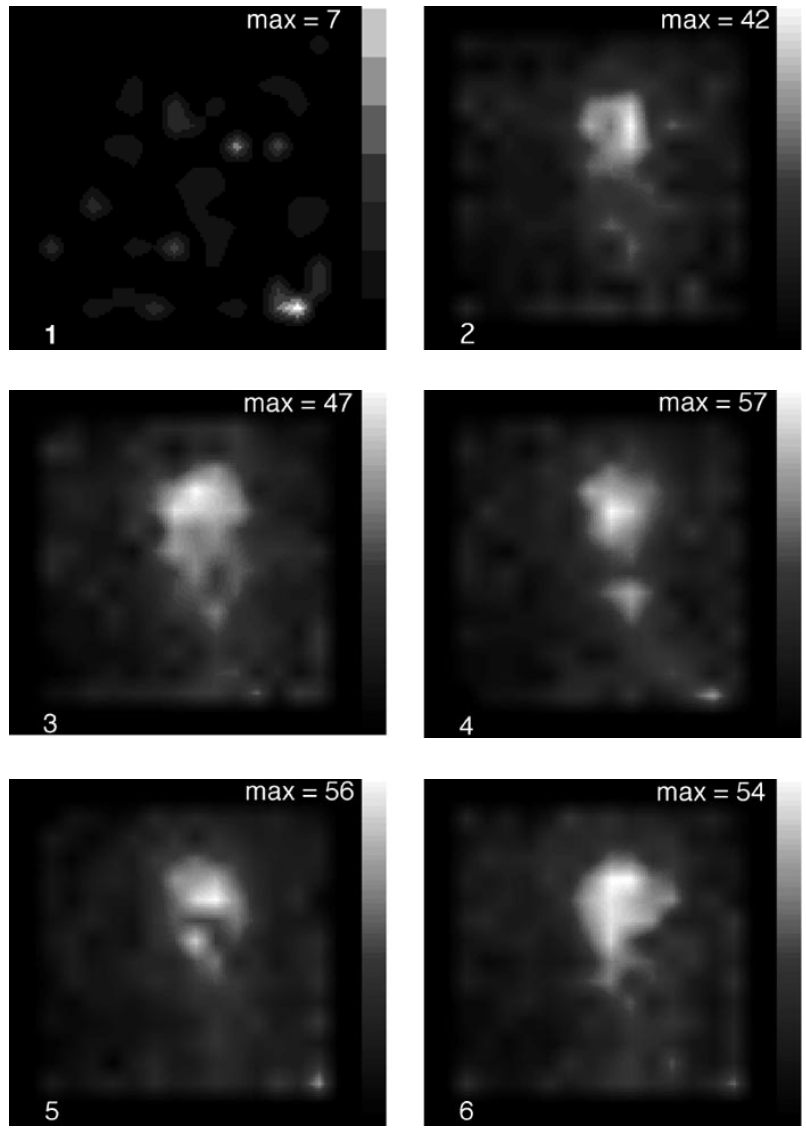

Fig. 9. A time series of images obtained with the mini gamma camera for the case shown in Fig. 8. Each image represents an acquisition time of $1 \mathrm{~min}$. The number of counts in the maximum pixel is indicated.

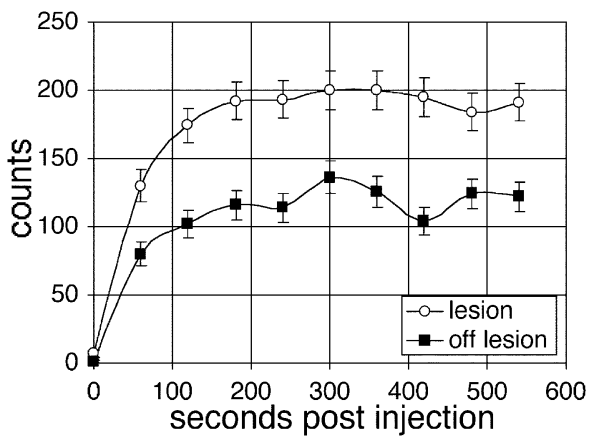

Fig. 10. Time activity curve for a 1-cm-square region of interest centered on the lesion and one centered just to the right and completely off the lesion.

uptake of MiraLuma by the lesion that is shown in the series of images in Fig. 9.

\section{CONCLUSION}

We have described the development of a dual-modality imaging system based on a compact gamma camera that is mounted to a commercial digital X-ray stereotactic core biopsy system to acquire a co-registered image. Preliminary results have shown that the system is capable of obtaining clinical data that could help evaluate the effectiveness of this application of scintimammography utilizing MiraLuma in predicting the malignancy of lesions identified by mammography. The system is presently being used to gather clinical data on the reliability of scintimammography in predicting the malignancy of suspected breast lesions.

\section{ACKNOWLEDGMENT}

The authors would like to thank the entire staff at the Riverside Diagnostic and Breast Imaging Center. They also thank C. Cuevas, B. Gunning, and D. Smith of the Jefferson Lab Fast Electronics Group for their valuable assistance with the electronics. Thanks also go to G. Franco for the machining of components of the detector head. They also thank Dupont Inc. for donating the needed doses of MiraLuma. Bicron Corporation's M. Lowdermilk and D. Herr and Hamamatsu Photonics' E. Baro and E. Hergert are thanked for providing, in a timely fashion, their high-quality scintillator arrays and PSPMTs, respectively. They also thank M. Smith for a careful reading of our manuscript. Finally, the authors wish to thank the reviewers for their valuable comments

\section{REFERENCES}

[1] J. Villanueva-Mayer, M. H. Leonard Jr., E. Briscoe, F. Cesani, S. A. Ali, S. Rhoden, M. Hove, and D. Cowan, "Mammoscintigraphy with technetium-99m-sestamibi in suspected breast cancer," J. Nucl. Med., vol. 37, no. 6, pp. 926-930, 1996.

[2] D. B. Kopans, "The positive predictive value of mammography," Amer. J. Roentgenol., vol. 158, pp. 521-526, 1992.

[3] I. Khalkhali, I. Mena, and L. Diggles, "Review of imaging techniques for the diagnosis of breast cancer: A new role of prone scintimammography using technetium-99m sestamibi," Eur. J. Nucl. Med., vol. 21, no. 4, pp. 357-362, 1994

[4] I. Khalkhali, I. Mena, E. Jouanne, L. Diggles, R. Venegas, J. Block, K. Alle, and S. Klein, "Prone scintimammography in patients with suspicion of carcinoma of the breast," J. Amer. College Surgeons, vol. 178, no. 5, pp. 491-497, 1994.

[5] I. Khalkhali, J. A. Cutrone, I. G. Mena, L. E. Diggles, R. J. Venegas, H. I. Vargas, B. L. Jackson, S. Khalkhali, J. F. Moss, and S. R. Klein, "Scintimammography: The complementary role of Tc-99m sestamibi prone breast imaging for the diagnosis of breast carcinoma," Radiology, vol. 196, no. 2, pp. 421-426, 1995.

[6] J. Tolmos, J. A. Cutrone, B. Wang, H. I. Vargas, M. Stuntz, F. S. Mishkin, L. E. Diggles, R. J. Venegas, S. R. Klein, and I. Khalkhali, "Scintimammographic analysis of nonpalpable breast lesions previously identified by conventional mammography," J. Nat. Cancer Inst., vol. 90, pp. 846-849, 1998.

[7] F. Scopinaro, R. Pani, G. de Vincentis, A. Soluri, R. Pellegrini, and L. M. Porfiri, "High-resolution scintimammography improves the accuracy of Tc-99m methoxyisobutylisonitrile scintimammography: Use of a new dedicated gamma camera," Eur. J. Nucl. Med., vol. 26, pp. 1279-1288, 1999.

[8] C. L. Maini, F. de Notaristefani, A. Tofani, F. Iacopi, R. Sciuto, A. Semprebene, T. Malatesta, F. Vittori, F. Fezza, C. Botti, S. Giunta, and P. Natali, "Tc-MIBI scintimammography using a dedicated nuclear mammograph," J. Nucl. Med., vol. 40, pp. 46-51, Jan. 1999.

[9] I. Khalkhali, F. S. Mishkin, L. E. Diggles, and S. R. Klein, "Radionuclide-guided sterotatic prebiopsy localization of nonpalpable breast lesions with normal mammograms," J. Nucl. Med., vol. 38, pp. 1019-1022, 1997.

[10] A. R. Goode, M. B. Williams, P. U. Simoni, V. Galbis-Reig, S. Majewski, A. G. Weisenberger, R. Wojcik, M. Stanton, W. Phillips, and A. Stewart, "A system for dual modality breast imaging," in Conf. Rec. $1999 \mathrm{Nu}$ clear Science Symp. Medical Imaging Conf., Seattle, WA, Oct. 23-31, 1999, CD-ROM.

[11] A. Truman, A. J. Bird, D. Ramsden, and Z. He, "Pixellated CsI(Tl) arrays with position-sensitive PMT readout," Nucl. Instrum. Methods Phys. Res. A, vol. 353, pp. 375-378, 1994.

[12] R. Pani, F. de Notaristefani, K. Blazek, P. Maly, R. Pellegrini, A. Pergola, A. Soluri, and F. Scopinaro, "Multi-crystal YAP:Ce detector system for position sensitive measurements," Nucl. Instrum. Methods Phys. Res. A, vol. 348, pp. 551-558, 1994. 
[13] F. Garibaldi, E. Cisbani, F. Cusanno, R. Iommi, G. M. Urciuoli, R. Pani, R. Pellegrini, R. Scafe, L. Indovina, M. N. Cinti, and G. Trotta, "Optimization of compact gamma cameras for breast imaging," Nucl. Instrum. Methods Phys. Res. A, vol. 471, no. 1, p. 222, 2001.

[14] S. Majewski, F. F. Farzanpay, A. Goode, B. Kross, D. Steinbach, A. Weisenberger, M. Williams, and R. Wojcik, "Development of an application specific scintimammography detector based on a crystal scintillator array and a PSPMT," Nucl. Instrum. Methods Phys. Res. A, vol. 409, no. $1-3$, p. 520, 1998

[15] M. B. Williams, A. R. Goode, V. Galbis-Reig, S. Majewski, A. G Weisenberger, and R. J. Wojcik, "Performance of a PSPMT based detector for scintimammography," Phys. Med. Biol., vol. 45, pp. 781-800, 2000.

[16] S. Majewski, E. Curran, C. Keppel, D. Kieper, B. Kross, A. Pulumbo, V. Popov, A. G. Weisenberger, B. Welch, R. Wojcik, M. B. Williams, A. R. Goode, M. More, and G. Zang, "Optimization of dedicated scintimammography procedure using detector prototypes and compressible phantoms," IEEE Trans Nucl. Sci., vol. 48, p. 822, June 2001.
[17] R. Pani, University "La Sapienza", Rome, Italy, private communication, Feb. 1997.

[18] R. Pani, A. Soluri, R. Scafe, A. Pergola, R. Pellegrini, G. De Vincentis, G. Trotta, and F. Scopinarol, "Multi-PSPMT scintillation camera," IEEE Trans Nucl. Sci., vol. 46, pp. 702-708, June 1999.

[19] L. Liberman, J. H. Smolkin, D. D. Dershaw, E. A. Morris, A. F. Abramson, and P. P. Rosen, "Calcification retrieval at stereotactic, 11-guage, directional, vacuum-assisted breast biopsy," Radiology, vol. 208, pp. 251-260, 1998.

[20] M. B. Williams, A. R. Goode, V. Galbis-Reig, S. Majewski, A. G. Weisenberger, and R. J. Wojcik, "Performance of a PSPMT based detector for scintimammography," Phys. Med. Biol., vol. 45, pp. 781-800, 2000

[21] R. L. Clancy, C. J. Thompson, J. L. Robar, and A. M. Bergman, “A simple technique to increase the linearity and field-of-view in position sensitive photomultiplier tube," IEEE Trans. Nucl. Sci., vol. 44, pp. 494-498, June 1997. 